\title{
Penile ulceration caused by a foreign body reaction in a crew member on board a cruise ship
}

\author{
Jenny Garcia-Castaneda, Alfredo Harb-De la Rosa
}

Ship Physicians, Miami, Fl, United States

\begin{abstract}
A crew member had a foreign body implanted subcutaneously on his dorsum penis stealthily 6 years earlier by a fellow crew member without any medical training. He presented to the ship's medical centre after a week of pain, erythema and oedema over the foreign body, which was eventually removed by the patient, leaving behind a penile ulceration. He was treated conservatively initially with intravenous and then with oral antibiotics until complete secondary wound closure was achieved.
\end{abstract}

(Int Marit Health 2015; 66, 1: 28-29)

Key words: foreign body reaction, penile ulceration, cruise ship

\section{CASE REPORT}

A 38-year-old Filipino crew member on a cruise ship presented with a penile ulcer. Six years earlier a fellow crew member without any medical training had implanted a foreign body subcutaneously on his dorsum penis. The post-insertion course was uneventful. A week before presentation, the skin over the foreign body became irritated and eventually ulcerated. He complained of pain, erythema and oedema on the affected area. He then removed the foreign body himself (Fig. 1) and sought medical attention aboard due to the presence of a penile ulceration. He denied any history of sexually transmitted disease as well as sexual activity over the past 3 months. History about masturbation episodes was not obtained. Family history was unremarkable. On physical examination, a $20 \times 9 \mathrm{~mm}$ ulcer (Fig. 2) was observed on the dorsum of his penis. Diagnosed with foreign body reaction, he was treated conservatively ( $48 \mathrm{~h}$ of intravenous antibiotics, then 10 days of oral antibiotics) and followed up daily until complete secondary wound closure was achieved after 2 weeks.

\section{DISCUSSION}

Throughout history, the presence of a large sexual organ has been regarded by men as an indicator of strong body composition, physical fitness and sexual prowess. It has been reported in the medical literature, that members of some primitive communities have undergone foreign body injection into the penis for augmentation purposes. This practice may still be popular in some Asian and eastern European countries [1]. Complications resulting from penile enlargement after insertion and injection of unknown types of material have also been described. These complications could be local or systemic. Some of the local complications include infection, ulceration, local migration and cavernosal invasion, which may lead to functional impairment. The most common reported local complications include penile paraffinomas and granulomas [2-5]. Systemic complications include foreign body embolisation, organ infarction and even death [6]. Rollins et al. [7] reported a patient who developed acute pulmonary oedema and died after self-administration of mineral oil into the scrotum. Delayed complications associated with penile augmentation procedures have also been reported [8]. In our case, complications appeared 6 years later which is quite remarkable given that the procedure was not carried out by experienced medical personnel and it was most likely performed without the appropriate aseptic measures. Interestingly enough, the procedure was performed on board a cruise ship in a cabin by non-medical personnel.

It is well known within the cruise industry that many crew members keep a side job on board in order to increase 


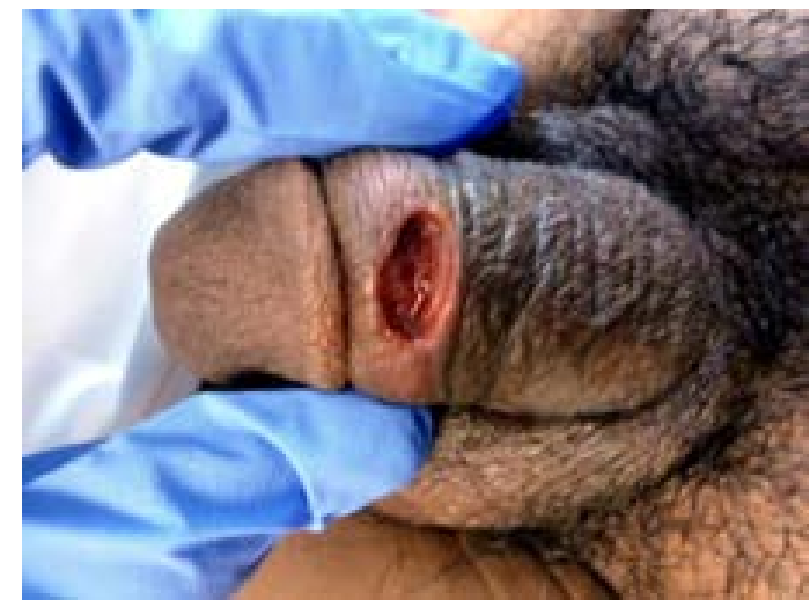

Figure 1. $20 \times 9 \mathrm{~mm}$ ulceration on crew member's dorsum penis resulting from foreign body removal

their revenue. It is therefore reasonable to deem these procedures as someone's side job. The obvious concerns are the level of expertise of the individual performing these procedures as well as the quality and safety of the materials and instruments employed.

To prevent further performance of these procedures on board, it is essential to educate crew members about the inherent risks and complications. Implementation of policies prohibiting this practice on board could also be effective.

To our knowledge, this manuscript reports the first case of complications associated with a penile augmentation procedure performed stealthily on board a cruise ship by non-medical personnel; however, this procedure and its complications are well known in Asian, particularly Filipino, seamen, while in non-Asians, this is more common in prison populations. This procedure is known as pearling, beading, marbling, etc., depending on the used material. Subcutaneous implantation of various foreign bodies on dorsum penis known as "boletas" in the Philippines, is done by "amateur surgeons", mostly seafarers without formal medical training working on merchant ships, therefore, we assume that this is not the first time that such a procedure has been carried out in a ship setting. The absence of previous publications could be based on the fact that crew members affected with similar complications might feel ashamed to seek medical

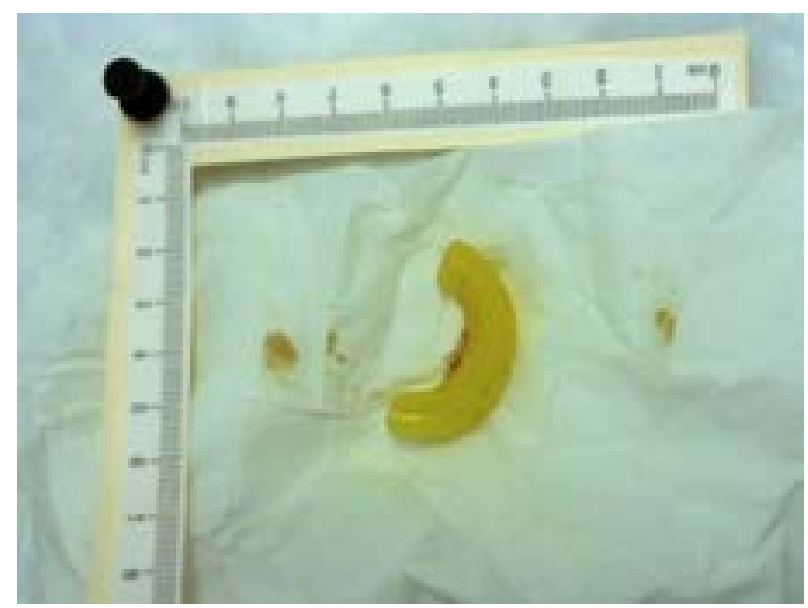

Figure 2. Foreign body removed by crew member from his dorsum penis

attention on board, or if they do, medical personnel were simply not interested in publishing such cases.

\section{CONCLUSIONS}

This case serves to make medical personnel on cruise ships aware of this type of practice and encourage them to advise crew members against it.

\section{REFERENCES}

1. Wiwanitkit V. Penile injection of foreign bodies in eight Thai patients. Sex Transm Infect 2004; 80: 546.

2. Wassermann RJ, Greenwald DP. Debilitating silicone granuloma of the penis and scrotum. Ann Plast Surg 1995; 35: 505-509; discussion 509-510.

3. Lighterman I. Silicone granuloma of the penis. Case reports. Plast Reconstr Surg 1976; 57: 517-519.

4. Christ JE, Askew JB Jr. Silicone granuloma of the penis. Plast Reconstr Surg 1982; 69: 337-339.

5. Pehlivanov G, Kavaklieva S, Kazandjieva J et al. Foreign-body granuloma of the penis in sexually active individuals (penile paraffinoma). J Eur Acad Dermatol Venereol 2008; 22: 845-851.

6. Inn FX, Imran FH, Ali MF etal. Penile augmentation with resultant foreign material granuloma and sequelae. Malays J Med Sci 2012; 19: 81-83.

7. Rollins CE, Reiber G, Guinee DG Jr. et al. Disseminated lipogranulomas and sudden death from self-administered mineral oil injection. Am J Forensic Med Pathol 1997; 18: 100-103.

8. Shaeer 0 , Shaeer K. Delayed complications of gel injection for penile girth augmentation. J Sex Med 2009; 6: 2072-2078. 